\title{
Advanced glycation end products and lipopolysaccharides stimulate interleukin-6 secretion via the RAGE/TLR4-NF-кB-ROS pathways and resveratrol attenuates these inflammatory responses in mouse macrophages
}

\author{
AYAKA OHTSU, YUI SHIBUTANI, KOTOMI SENO, HISATAKA IWATA, \\ TAKEHITO KUWAYAMA and KOUMEI SHIRASUNA \\ Laboratory of Animal Reproduction, Department of Animal Science, \\ Tokyo University of Agriculture, Atsugi, Kanagawa 234-0034, Japan \\ Received February 2, 2016; Accepted February 14, 2017
}

DOI: $10.3892 /$ etm.2017.5045

\begin{abstract}
Macrophages are essential for regulating the physiology of pregnancy; however, excessive inflammatory responses to macrophages, induced by infection and/or endogenous danger signals, may potentially result in complications during pregnancy. Advanced glycation end-products (AGE) and lipopolysaccharides (LPS) are known to induce inflammation and are associated with adverse developmental outcomes. The aim of the present study was to examine the effect of AGE and LPS on cytokines in the J774 murine macrophage cell line and the potential effect of resveratrol on AGE- and LPS-induced inflammation in macrophages. AGE and LPS significantly increased IL-6 mRNA expression and secretion in J774 macrophages $(\mathrm{P}<0.05)$. Although AGE and LPS significantly stimulated IL-1 $\beta$ mRNA expression $(\mathrm{P}<0.05)$, they had no significant effect on IL-1 $\beta$ secretion. To assess the receptors for AGE and LPS, including receptor for AGE (RAGE) and Toll-like receptor (TLR4), blocking reagents (RAGE antagonist or TLR4 inhibitor) were added to the J774 macrophages. IL-6 secretion induced by AGE or LPS was significantly inhibited by pretreatment with RAGE antagonist $(\mathrm{P}<0.05)$ or TLR4 inhibitor $(\mathrm{P}<0.05)$. IL-6 secretion was dependent on nuclear factor $(\mathrm{NF})-\kappa \mathrm{B}$ activation and the production of reactive oxygen species (ROS; $\mathrm{P}<0.05)$. Resveratrol suppressed mRNA expression and intracellular IL-6 production, resulting in significantly decreased IL-6 secretion after treatment with LPS or AGE $(\mathrm{P}<0.01)$. Furthermore, treatment with Ex527, which is a sirtuin-1 (SIRT1) inhibitor, significantly attenuated
\end{abstract}

Correspondence to: Dr Koumei Shirasuna, Laboratory of Animal Reproduction, Department of Animal Science, Tokyo University of Agriculture, 1737 Funako, Atsugi, Kanagawa 234-0034, Japan E-mail: ks205312@nodai.ac.jp

Key words: advanced glycation end products, lipopolysaccharides, macrophages, inflammation, resveratrol the anti-inflammatory effect of resveratrol $(\mathrm{P}<0.05)$, and treatment with 5-aminoimidazole-4-carboxamide ribonucleotide, which is a $5^{\prime}$ adenosine monophosphate-activated protein kinase (AMPK) activator, resulted in a significant decrease in IL-6 secretion in $\mathrm{J} 774$ macrophages $(\mathrm{P}<0.05)$. The results of the present study indicated that AGE and LPS increase IL-6 secretion depending on NF- $\kappa \mathrm{B}$ activation and ROS production through RAGE and/or TLR4 in the $\mathbf{J 7 7 4}$ murine macrophage cell line. Based on the present study, resveratrol appears to be an effective regulator of the inflammatory responses associated with SIRT1 and AMPK activation in macrophages. These results suggest that resveratrol may have therapeutic applications for controlling immune responses during pregnancy.

\section{Introduction}

The immune system includes macrophages, natural killer cells, and T lymphocytes, and is essential for regulating pregnancy in mammals (1). In particular, macrophages are crucial for regulating the physiology of pregnancy, including ovarian function, maternal recognition of the fetus, implantation, placentation, and parturition (2). For example, macrophage depletion following conception causes embryo implantation arrest, which is associated with decreased plasma progesterone due to the disruption of the luteal microvascular network (3). Macrophages secrete a variety of cytokines during pregnancy, including pro-inflammatory cytokines [interleukin (IL)-6, tumor necrosis factor (TNF)- $\alpha$ and interferon- $\gamma]$ and anti-inflammatory cytokines (IL-4 and IL-10) (1). However, infection and/or endogenous danger signals induce excessive inflammatory responses in macrophages, which may potentially result in pregnancy complications including preeclampsia, preterm delivery, and poor fetal growth (4-7).

It has been reported that bacterial infection during pregnancy is the prevailing cause of preterm labor and affects $5-10 \%$ of all pregnancies $(8,9)$. The cell walls of gram-negative bacteria contain lipopolysaccharide (LPS), which is known to induce inflammation and has been associated with adverse developmental outcomes $(7,10)$. Maternal exposure to LPS 
has been demonstrated to induce embryonic resorptions, fetal death, and fetal absorption in mice $(7,10)$. Additionally, it has previously been reported that endogenous danger signals may contribute to the pathogenesis of pregnancy complications, such as preeclampsia and preterm labor (11-14). Advanced glycation end products (AGE) are heterogeneous, reactive, and irreversibly crosslinking molecules formed by the non-enzymatic glycation of proteins, lipids, and nucleic acids (11), and are one of the endogenous danger signals in pregnancy. Similar to the adverse effects of LPS, AGE have been implicated in the pathogenesis of infertility as they reduce the formation of blastocysts $(15,16)$. In general, AGE and/or LPS interact with the AGE receptor (RAGE) and/or Toll-like receptor 4 (TLR4) to induce inflammatory responses (cytokine production) $(17,18)$.

The phytoalexin resveratrol (3,5,4'-trihydroxystilbene) is a non-flavonoid polyphenolic compound that provides the cardiovascular benefits of red wine $(19,20)$. It has been demonstrated that resveratrol has multipotent benefits, including anti-cancer and anti-oxidant effects, inflammation reduction, and metabolic and vascular function improvement (19-23). Resveratrol may therefore be a powerful tool for protecting against the deleterious effects of excessive caloric intake, modulating energy balance, and promoting good health and longevity $(22,24)$. Furthermore, the beneficial effects of resveratrol are putatively assumed to be due to sirtuin 1 (SIRT1), cAMP, or 5' adenosine monophosphate-activated protein kinase (AMPK) pathway activation $(22,25)$.

Understanding how AGE and LPS induce inflammation, and how resveratrol exerts its effects, is important, not only for potential insights into the biological causes of inflammation-related diseases but also to allow for the development of pharmacological agents that have similar effects with resveratrol. In the present study, the effects of AGE and LPS on inflammatory cytokine production in a mouse $\mathrm{J} 774$ cell line were investigated. The potential effect of resveratrol on AGE- and LPS-induced inflammation in macrophages was also examined.

\section{Materials and methods}

Cell culture and experimental conditions. Murine J774 macrophages were obtained from RIKEN BioResource Center (Tsukuba, Japan) and cultured at $37^{\circ} \mathrm{C}$ until confluence was reached in Dulbecco's modified Eagle's medium/F-12 (Thermo Fisher Scientific, Inc., Waltham, MA, USA) supplemented with antibiotics including amphotericin B and gentamicin (Sigma-Aldrich, St Louis, MA, USA), and 5\% fetal bovine serum (ICN Pharmaceuticals, Inc., Costa Mesa, CA, USA). The $\mathrm{J} 774$ cells were seeded at a concentration of $2.5 \times 10^{5}$ cells/well in a 24-well culture plate (Thermo Fisher Scientific Inc.).

To examine cytokine secretion, mRNA expression and protein expression, cells were washed twice with PBS and treated for $24 \mathrm{~h}$ with the following 7 groups: Different concentratins of bovine serum albumin (BSA; 100, 200, or $400 \mu \mathrm{g} / \mathrm{ml}$; BioVision, Inc., Milpitas, CA, USA), different concentrations of AGE-BSA $(100,200$, or $400 \mu \mathrm{g} / \mathrm{ml}$; BioVision, Inc.), and LPS $(0.1 \mu \mathrm{g} / \mathrm{ml}$; Sigma-Aldrich). BSA at the same concentration as each AGE-BSA treatment was used as vehicle control. Supernatants were collected for ELISA (described in the western blotting section), RNA was collected for reverse transcription-quantitative polymerase chain reaction (RT-qPCR) using ISOGEN (Nippon Gene Co., Ltd., Tokyo, Japan) according to the manufacturer's protocol, and cell lysates were collected for western blot analysis using radioimmunoprecipitation assay buffer (described later). Samples were stored at -20 or $-80^{\circ} \mathrm{C}$ before analysis.

In the experiments studying receptor inhibition in AGE- or LPS-induced IL-6 secretion, J774 macrophages were stimulated with either AGE or LPS in the absence or presence of either RAGE antagonist (10 $\mu \mathrm{M}$; FPS-XM1; Merck Millipore, Darmstadt, Germany) or TLR4 inhibitor (10 $\mu \mathrm{M}$; NBP2-26244; Novus Biologicals, LLC, Littleton, CO, USA). To evaluate the role of nuclear factor $(\mathrm{NF})-\kappa \mathrm{B}$, cells were pre-incubated for $1 \mathrm{~h}$ at $37^{\circ} \mathrm{C}$ with an $\mathrm{NF}-\kappa \mathrm{B}$ activation inhibitor $(150 \mathrm{nM}$; NF- $\kappa \mathrm{B}$ activation inhibitor IV; Merck Millipore) prior to the addition of AGE or LPS. To investigate the role of reactive oxygen species (ROS), J774 macrophages were pre-incubated for $1 \mathrm{~h}$ at $37^{\circ} \mathrm{C}$ in the absence or presence of $\mathrm{N}$-acetyl-L-cysteine $(1 \mathrm{mM}$; NAC; Wako Pure Chemical Industries, Ltd. Osaka, Japan) for $1 \mathrm{~h}$ and subsequently treated with either AGE or LPS for $24 \mathrm{~h}$ at $37^{\circ} \mathrm{C}$.

To investigate the effect of resveratrol, J774 macrophages were pretreated with ethanol as a control solvent of resveratrol, or resveratrol $(2,20$, or $50 \mu \mathrm{M}$; Wako Pure Chemical Industries, Ltd.) for $1 \mathrm{~h}$ at $37^{\circ} \mathrm{C}$ and subsequently stimulated with AGE or LPS. To evaluate the role of AMPK and SIRT1 on resveratrol function, cells were pretreated with resveratrol in the absence or presence of 5-aminoimidazole-4-carboxamide ribonucleotide (AICAR; $10 \mu \mathrm{M}$, Sigma-Aldrich), which is an AMPK activator, or SIRT1 inhibitor Ex-527 (20 $\mu \mathrm{M}$, Sigma-Aldrich), respectively, for $1 \mathrm{~h}$ at $37^{\circ} \mathrm{C}$ and subsequently stimulated with LPS.

Determination of cytokines. After treatment as described above, supernatants were collected in $1.5 \mathrm{ml}$ tubes and stored at $-20^{\circ} \mathrm{C}$. Levels of IL- 6 and IL-1 $\beta$ were determined using a mouse ELISA kit (DY406 and DY401; R\&D Systems, Inc., Minneapolis, MN, USA) according to the manufacturer's protocol. A total of 4 repeats were conducted for each group.

$R T-q P C R$. Total RNA was prepared using ISOGEN (Nippon Gene Co., Ltd.) according to the manufacturer's protocol. RNA extraction and cDNA production were performed a commercial kit (ReverTra Ace; Toyobo Co., Ltd., Osaka, Japan) as described previously (26). RT-qPCR was performed using the CFX Connect Real Time PCR cycler (Bio-Rad Laboratories, Inc., Hercules, CA, USA) and a commercial kit (Thunderbird SYBR qPCR Mix; Toyobo Co., Ltd.) to detect the expressions of IL-6, IL-1 $\beta$, and GAPDH mRNA. The following antisense and sense primers were used: IL-6, forward 5'-ACAACCACG GCCTTCCCTACTT-3' and reverse 5'-CACGATTTCCCA GAGAACATGTG-3'; IL-1 $\beta$, forward 5'-TGAAGTTGACGG ACCCCAAA-3' and reverse 5'-TGATGTGCTGCTGTGAGA TT-3'; and GAPDH forward 5'-TGTGTCCGTCGTGGATCT GA-3' and reverse 5'-TTGCTGTTGAAGTCGCAGGAG-3'. RT-qPCR was performed in duplicate with a final reaction volume of $20 \mu \mathrm{l}$ containing $10 \mu \mathrm{l} \mathrm{SYBR-Green,} 7.8 \mu \mathrm{l}$ distilled water, $0.1 \mu \mathrm{l} 100 \mu \mathrm{M}$ forward and reverse primers, and $2 \mu \mathrm{l}$ of cDNA template. The amplification program consisted of a 5 min denaturation at $95^{\circ} \mathrm{C}$ followed by 40 cycles of amplification $\left(95^{\circ} \mathrm{C}\right.$ for $15 \mathrm{sec}, 60^{\circ} \mathrm{C}$ for $30 \mathrm{sec}$, and $72^{\circ} \mathrm{C}$ for $\left.20 \mathrm{sec}\right)$. Expression levels of each target gene were normalized to the 
corresponding GAPDH threshold cycle values using the $2^{-\Delta \Delta \mathrm{Cq}}$ comparative method (27).

Immunocytochemistry. To evaluate the expression of RAGE and TLR4, J774 macrophages were washed twice with PBS and blocked with 5\% BSA in PBS for $1 \mathrm{~h}$ at room temperature. Cells were subsequently incubated with RAGE $(1: 1,000$; ab3611; Abcam, Cambridge, MA, USA) and TLR4 antibodies (1:500; ab22048; Abcam) for $90 \mathrm{~min}$ at room temperature followed by incubation for $1 \mathrm{~h}$ at room temperature with a secondary Alexa 488-conjugated antibody $(1: 1,000$; cat. no. 4412; Cell Signaling Technology, Inc., Danvers, MA, USA). The cells were covered with Vectershield and stained with 4'6-diamidino-2-phenylindole (Vector Laboratories, Inc., Burlingame, CA, USA). The stained sections were examined using a fluorescence microscope (DMI6000B; Leica Microsystems Inc., Buffalo Grove, IL, USA) and LAS AF software (version 3; Leica Microsystems Inc.).

Western blot analysis. Lysates from the cell culture were prepared using radioimmunoprecipitation assay buffer (RIPA buffer; Wako Pure Chemical Industries, Ltd.). Cells were subsequently washed with cold PBS and incubated with RIPA buffer for $15 \mathrm{~min}$ on ice. Cell lysates were subsequently transferred into $1.5 \mathrm{ml}$ tubes and centrifuged at $12,000 \mathrm{x} g$ for $20 \mathrm{~min}$ at $4^{\circ} \mathrm{C}$. Supernatants were transferred to a fresh tube and stored at $-80^{\circ} \mathrm{C}$ before analysis. A total of $10 \mu \mathrm{g}$ protein was loaded per lane and separated by $10 \%$ SDS-PAGE. The expression of $\mathrm{NF}-\kappa \mathrm{B}$ p65 and $\beta$-actin were analyzed using SDS-PAGE. Lysates were transferred onto polyvinylidene fluoride membranes and blocked for $1 \mathrm{~h}$ at room temperature using Immunoblock (DS Pharma Biomedical Co., Ltd., Osaka, Japan). Membranes were washed with TBST wash buffer and incubated for $24 \mathrm{~h}$ at $4^{\circ} \mathrm{C}$ with anti-NF- $\kappa \mathrm{B}$ p65 subunit antibody (1:1,000; cat. no. MAB3026; Merck Millipore), or anti- $\beta$-actin antibody (1:10,000; AC-74; Sigma-Aldrich), followed by incubation for $1 \mathrm{~h}$ at room temperature with a horseradish peroxidase (HRP)-conjugated secondary antibody (1:1,000; NA934; GE Healthcare Life Sciences, Chalfont UK). Immunoreactive bands were visualized with Western BLoT Quant HRP Substrate (GE Healthcare Life Sciences) using ImageQuant LAS 4000 (GE Healthcare Life Sciences). Western blotting was performed in duplicate.

Statistical analysis. All data are expressed as mean \pm standard error of the mean. Differences between treatment groups were identified using unpaired t-tests. Multiple group comparisons were made using one-way analysis of variance followed by Bonferroni's multiple comparison tests using Statview version 5.0 (SAS Institute, Cary, NC, USA). $\mathrm{P}<0.05$ was considered to indicate a statistically significant difference.

\section{Results}

Effects of AGE and LPS on IL-6 and IL-1 $\beta$ in J774 macrophages. The effects of AGE or LPS on inflammatory responses including IL-6 secretion and production from J774 macrophages were examined (Fig. 1A). IL-6 secretion was significantly upregulated by treatment with $\geq 200 \mu \mathrm{g} / \mathrm{ml}$ AGE
$(\mathrm{P}<0.05)$ or LPS $(\mathrm{P}<0.01)$, whereas the BSA vehicle had no significant effect (Fig. 1A). Similarly, AGE and LPS treatments also increased IL-6 mRNA expression of J774 macrophages (AGE, P<0.05; LPS, P<0.01; Fig. 1B). Treatment with AGE or LPS had no significant effect on IL-1 $\beta$ secretion (Fig. 1C), whereas the expression of IL-1 $\beta$ mRNA was significantly upregulated by AGE $(\mathrm{P}<0.05)$ and LPS $(\mathrm{P}<0.01$; Fig. 1D).

Role of RAGE and TLR4 on AGE- or LPS-induced IL-6 secretion. RAGE and TLR4 are two of the major receptors for AGE and LPS, respectively $(17,18)$. In the present study, it was first confirmed via immunofluorescence that these two receptors were expressed in $\mathbf{J} 774$ macrophages (Fig. 2A and B). To investigate the receptor involved in AGE- and LPS-induced IL-6 secretion, blocking reagents (RAGE antagonist or TLR4 inhibitor) were added to the J774 macrophages, followed by the addition of either AGE or LPS, at $1 \mathrm{~h}$ following treatment with the blocking reagent. The results revealed that AGE-induced IL-6 secretion was significantly inhibited by pretreatment with either the RAGE antagonist or TLR4 inhibitor $(\mathrm{P}<0.05$; Fig. 2C and D). Furthermore, LPS-induced IL-6 secretion was significantly blocked by pretreatment with TLR4 inhibitor $(\mathrm{P}<0.01$; Fig. 2E).

Role of NF- $\mathrm{BB}$ and ROS on AGE-or LPS-induced IL-6 secretion. $\mathrm{NF}-\kappa \mathrm{B}$ is a key transcription factor for the induction of inflammatory cytokines, such as IL-6 (28). Treatment with AGE or LPS induced a notable upregulation of the NF- $\kappa$ B p65 protein content in $\mathrm{J} 774$ macrophages (Fig. 3A). Treatment with an $\mathrm{NF}-\kappa \mathrm{B}$ inhibitor significantly reduced the secretion of IL-6 induced by $\mathrm{AGE}(\mathrm{P}<0.05$; Fig. $3 \mathrm{~B})$ or LPS $(\mathrm{P}<0.01$; Fig. $3 \mathrm{C})$, suggesting that both AGE and LPS stimulate IL-6 secretion in an $\mathrm{NF}-\kappa \mathrm{B}$-dependent manner.

It has previously been demonstrated that AGE and LPS stimulate ROS production $(16,29,30)$. Therefore, IL-6 secretion induced by treatment with AGE or LPS suggests that ROS production involves AGE- and LPS-induced inflammation. To investigate the importance of ROS in AGE- and LPS-induced inflammation, the effects of the antioxidant NAC on J774 macrophages were investigated. Pretreatment with NAC significantly inhibited IL-6 secretion from J774 macrophages treated with either AGE $(\mathrm{P}<0.05)$ or LPS $(\mathrm{P}<0.01$; Fig. 3D and E). These data indicate that ROS production is a key factor in danger signal-induced IL-6 secretion in murine macrophages.

Role of resveratrol in AGE- or LPS-induced IL-6 secretion. J774 macrophages were treated with various concentrations of resveratrol to check the inhibitory function for an inflammatory response. IL-6 secretion was significantly elevated in the supernatants of LPS-treated J774 macrophages compared with the control group $(\mathrm{P}<0.01$; Fig. 4A). Cells were treated with different doses of resveratrol, with ethanol as a vehicle control, and resveratrol was found to significantly decrease LPS-induced IL-6 secretion in a dose-dependent manner $(\mathrm{P}<0.05$; Fig. 4A). Furthermore, AGE-induced IL-6 secretion was significantly inhibited by treatment with resveratrol $(\mathrm{P}<0.05$; Fig. 4B). To further investigate the function of resveratrol, LPS was chosen as a stimulus due to the greater inflammatory response to LPS compared with AGE. 
A

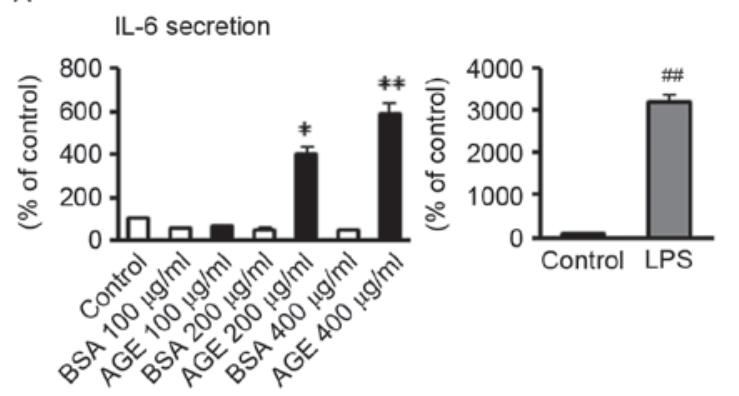

B

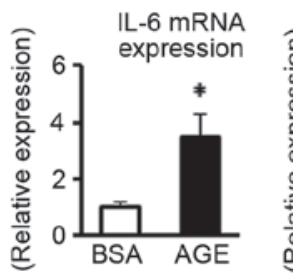

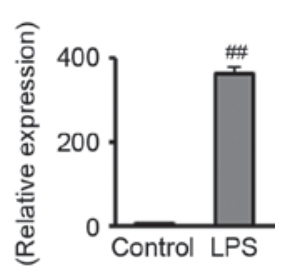

C IL-1 $\beta$ secretion

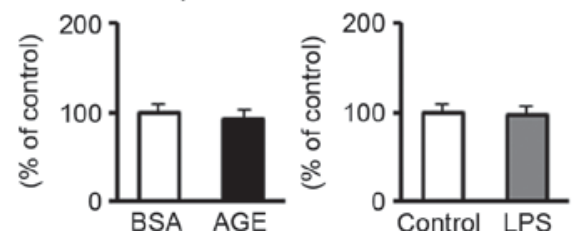

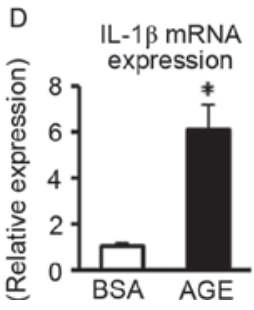

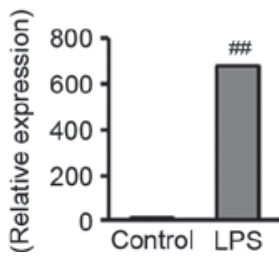

Figure 1. Effects of AGE and LPS on IL-6 and IL-1 $\beta$ from J774 macrophages. J774 macrophages were incubated for $24 \mathrm{~h}$ in the presence of either AGE or LPS. (A) IL-6 levels in supernatant were determined using ELISA. (B) The IL- 6 mRNA levels was assessed by RT-qPCR. (C) IL-1 $\beta$ levels in supernatant were determined using ELISA. (D) The IL-1 $\beta$ mRNA levels was assessed by RT-qPCR. Data are expressed as the mean \pm standard error of the mean. $\mathrm{n}=4$ for each experiment. " $\mathrm{P}<0.05$ and ${ }^{* *} \mathrm{P}<0.01$ vs. BSA, ${ }^{\# \#} \mathrm{P}<0.01$ vs. control. AGE, advanced glycation end-products; LPS, lipopolysaccharides; IL, interleukin; RT-qPCR, reverse transcription-quantitative polymerase chain reaction; BSA, bovine serum albumin.

A

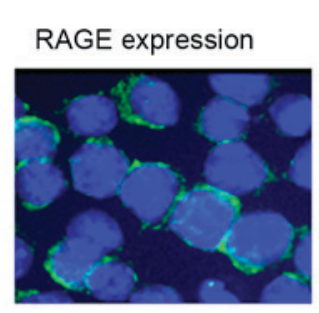

B

TLR4 expression

C

IL-6 secretion

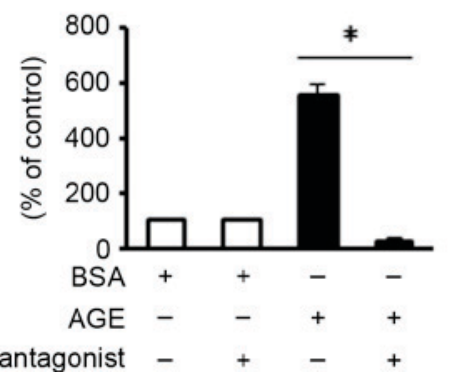

D

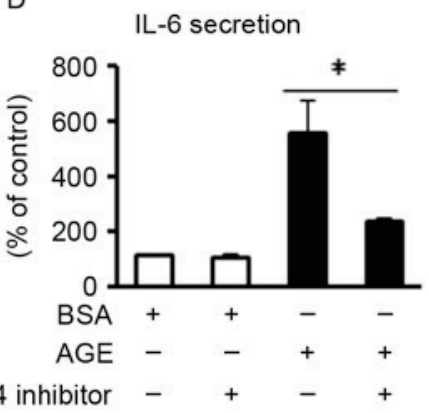

E

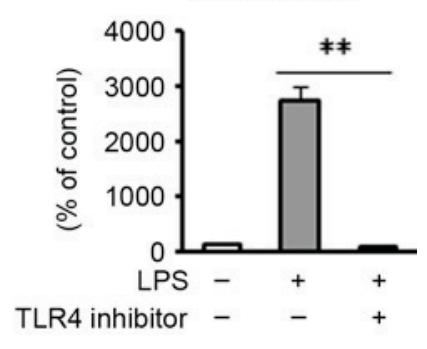

Figure 2. Role of RAGE and TLR4 on AGE- or LPS-induced IL-6 secretion. (A and B) J774 macrophages were stained with RAGE or TLR4 antibody with 4', 6-diamidino-2-phenylindole. (C-E) J774 macrophages were pre-incubated with or without RAGE antagonist or TLR-4 inhibitor for $1 \mathrm{~h}$; cells were further incubated for $24 \mathrm{~h}$ with or without AGE or LPS. IL-6 levels in supernatant were determined using ELISA. Data are expressed as the mean \pm standard error of the mean $\mathrm{n}=4$ for each experiment. ${ }^{*} \mathrm{P}<0.05,{ }^{* *} \mathrm{P}<0.01$. AGE, advanced glycation end-products; RAGE, receptor for AGE; TLR4, Toll-like receptor; LPS, lipopolysaccharides; IL, interleukin; BSA, bovine serum albumin.

LPS treatment was also found to markedly increase the level of intracellular IL-6 and mRNA expression of IL-6 in J774 macrophages (Fig. 4C and D). Resveratrol treatment significantly attenuated this increase $(\mathrm{P}<0.01$; Fig. $4 \mathrm{C}$ and $\mathrm{D})$, suggesting that resveratrol attenuates LPS-induced IL-6 transcription, production, and secretion in J774 macrophages.

It has been reported that resveratrol activates SIRT1 and AMPK in cell culture and in vivo $(22,25)$. In the present study, the functional role of resveratrol was investigated using
Ex-527 and AICAR in LPS-induced IL-6 secretion. It was also investigated whether the effect of resveratrol on LPS-induced IL-6 secretion was dependent on SIRT1. Treatment with Ex-527+ethanol had no significant effect on LPS-induced IL-6 secretion from macrophages (Fig. 4E). Although resveratrol treatment suppressed LPS-induced IL-6 secretion, Ex-527 treatment significantly reversed this effect $(\mathrm{P}<0.05$; Fig. 4E). Pretreatment with AICAR had a similar effect to treatment with resveratrol, significantly inhibiting LPS-induced IL-6 secretion from macrophages $(\mathrm{P}<0.05$; Fig. $4 \mathrm{~F})$. These data 


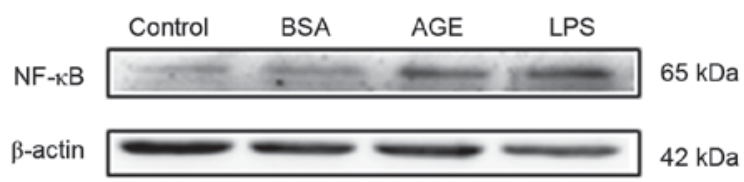

B

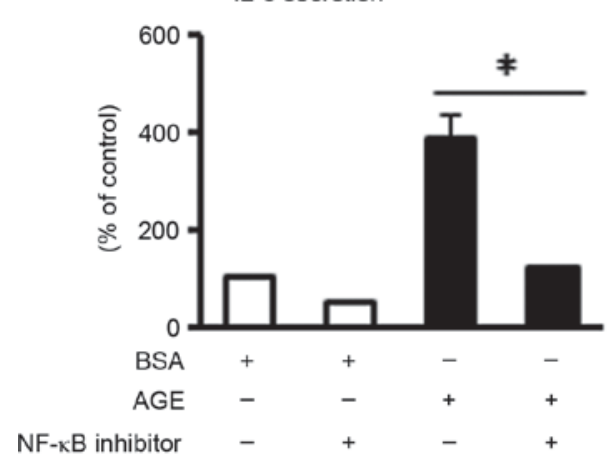

C

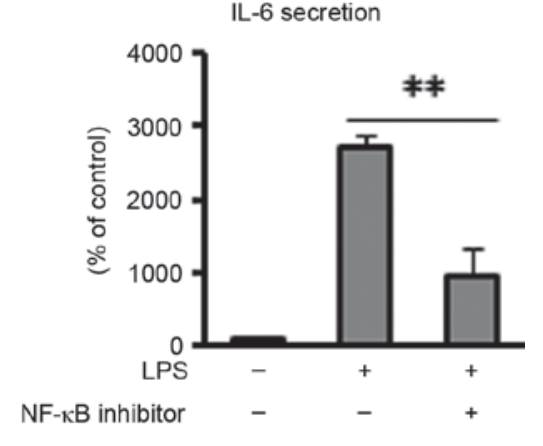

$\mathrm{D}$

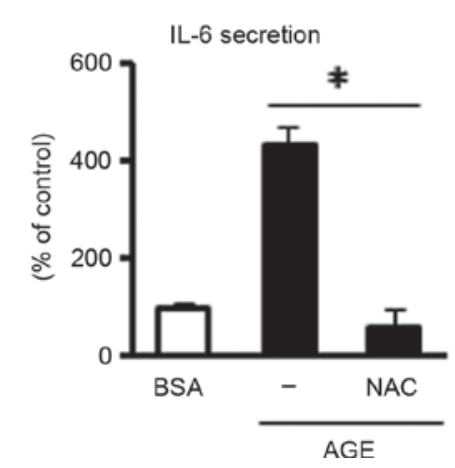

E IL-6 secretion

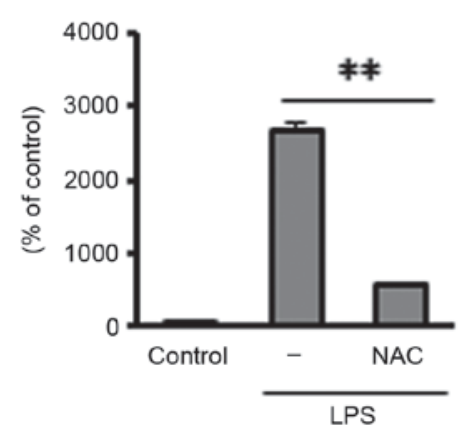

Figure 3. Role of NF-kB activation and ROS production on AGE- or LPS-induced IL-6 secretion. (A) J774 macrophages were incubated for $24 \mathrm{~h}$ in the absence or presence of AGE or LPS. Representative results of NF- $\mathrm{BB}$ and $\beta$-actin immunoblots are displayed. (B and C) J774 macrophages were pre-incubated with or without NF- $\mathrm{kB}$ inhibitor for $1 \mathrm{~h}$; cells were further incubated for $24 \mathrm{~h}$ with or without AGE or LPS. (D and E) J774 macrophages were pre-incubated using ROS inhibitors (NAC) for $1 \mathrm{~h}$; cells were further incubated for $24 \mathrm{~h}$ with or without AGE or LPS. IL-6 levels in supernatant were determined using ELISA. Data are expressed as the mean \pm standard error of the mean, $n=4$ for each experiment. ${ }^{*} \mathrm{P}<0.05,{ }^{* *} \mathrm{P}<0.01$. NF, nuclear factor; ROS, reactive oxygen species; AGE, advanced glycation end-products; LPS, lipopolysaccharides; IL, interleukin; NAC, $N$-acetyl-L-cysteine.

suggest that SIRT1 and AMPK serve a role in mediating the benefits of resveratrol.

\section{Discussion}

There is increasing evidence that suggests both AGE and LPS are associated with inflammation. Numerous studies have indicated that AGE and LPS promote pro-inflammatory mediator production, such as IL-6, IL-1 $\beta$, and TNF $\alpha$, from a variety of cell types including macrophages, placenta, chondrocytes, and endothelial cells (16,17,31-36). In the present study, it was demonstrated that AGE and LPS increased IL-6 secretion following the induction of IL-6 mRNA expression in J774 murine macrophage cell lines. It is well known that LPS regulates macrophage polarization toward M1-type inflammatory activity. Jin et al (37) reported that AGE significantly promotes inflammatory cytokines and a surface marker of M1-type macrophages, and does not affect M2-type macrophage markers in mouse bone-marrow-derived macrophages. Therefore, both AGE and LPS enhance macrophage differentiation into pro-inflammatory M1 phenotype.

IL-1 $\beta$ is one of the major pro-inflammatory cytokines produced by immune cells $(38,39)$. Initially, a stimulus is required to produce the precursor of IL-1 $\beta$ (pro-IL-1 $\beta$ ) in the cells. IL-1 $\beta$ secretion is subsequently regulated by caspase-1 (also known as an IL-1 $\beta$-converting enzyme) due to inflammasome activation, including that of NLRP3 inflammasomes $(38,39)$. Although treatment with AGE and LPS significantly upregulated IL- $1 \beta$ mRNA expression, these stimuli had no effect on IL-1 $\beta$ secretion in J774 macrophages. This suggests that AGE and LPS have roles in pro-IL-1 $\beta$ production but not in inflammasome activation.

AGE and/or LPS bind to and signal through multivalent receptors such as RAGE and/or TLRs (TLR2 and TLR4) $(40,41)$. In the present study, the expression of two major receptors, RAGE and TLR4, was confirmed in J774 macrophages. These 


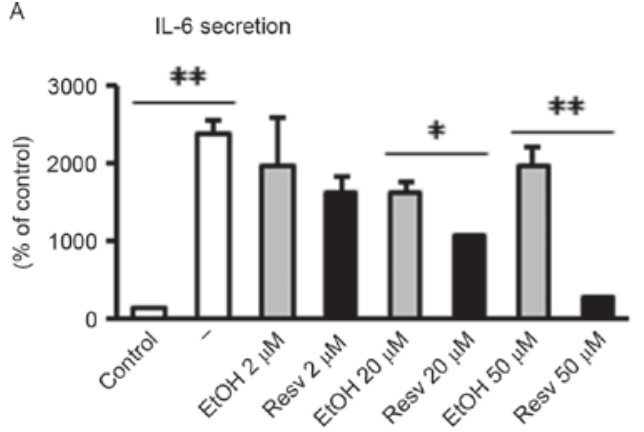

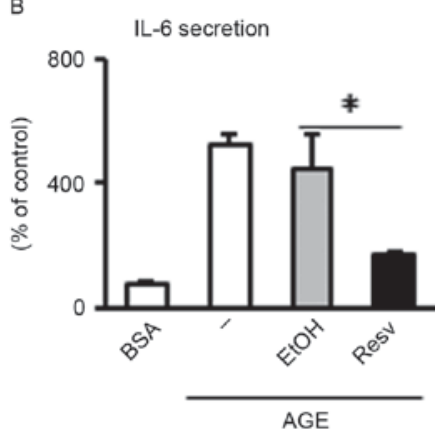

LPS

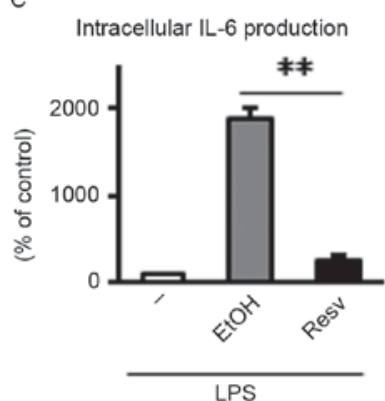

E

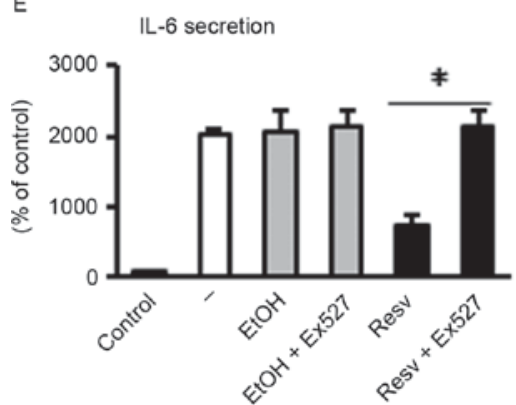

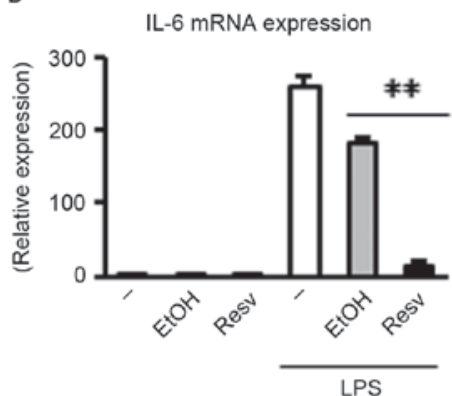

F

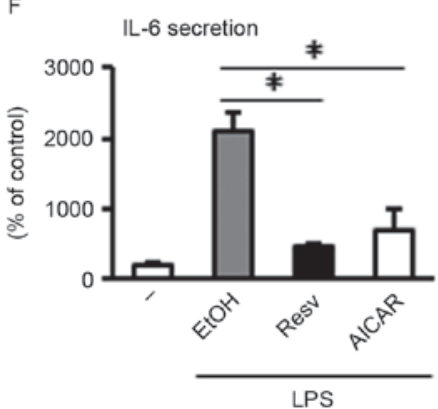

LPS

Figure 4. Role of resveratrol on AGE- or LPS-induced IL-6 secretion. (A-D) J774 macrophages were pre-incubated using EtOH or resveratrol for 1 h; cells were further incubated for $24 \mathrm{~h}$ with or without AGE or LPS. IL-6 levels in (A and B) the supernatant and (C) intracellular were determined using ELISA. (D) The IL- 6 mRNA levels was assessed by reverse transcription-quantitative polymerase chain reaction. (E) J774 macrophages were pre-incubated using EtOH or resveratrol with or without Ex 527; cells were further incubated for 24 h with or without LPS. (F) J774 macrophages were pre-incubated using EtOH, resveratrol, or AICAR for $1 \mathrm{~h}$; cells were further incubated for $24 \mathrm{~h}$ with or without LPS. IL-6 levels in supernatant were determined using ELISA. Data are expressed as the mean \pm standard error of the mean. $\mathrm{n}=4$ for each experiment. ${ }^{*} \mathrm{P}<0.05,{ }^{* *} \mathrm{P}<0.01$. AGE, advanced glycation end-products; LPS, lipopolysaccharides; IL, interleukin; EtOH, ethanol; AICAR, 5-aminoimidazole-4-carboxamide ribonucleotide; Resv, resveratrol; BSA, bovine serum albumin.

receptors were then blocked in turn to evaluate which receptor was involved in the inflammatory effect. Blocking RAGE or TLR4 abolished AGE-induced inflammation, and the TLR-4 inhibitor abolished LPS-induced IL-6 secretion in J774 macrophages. Similarly, using neutralization antibody or small interfering RNA techniques, it was previously demonstrated that AGE stimulated IL-6 secretion via RAGE and/or TLR4, whereas LPS enhanced it via TLR4 $(16,34,37,42)$.

$\mathrm{NF}-\kappa \mathrm{B}$ is a key component in inflammatory cytokine production (28). AGE and LPS have been demonstrated to significantly increase the release of IL-6, depending on NF- $\mathrm{BB}$ activation in various types of cells in vitro. Liu et al (33) demonstrated that stimulation with both AGE and LPS induces nuclear translocation of $N F-\kappa B$. In the present study it was confirmed that when $N F-\kappa B$ was inhibited, AGE and LPS increased IL-6 secretion depending on NF- $\kappa \mathrm{B}$ activation. These findings suggest that both AGE and LPS directly induce inflammation responses via the RAGE and/or TLR4-NF- $\kappa$ B activation pathway.

ROS are commonly considered as harmful mediators of acute inflammation $(43,44)$. It is well understood that both AGE and LPS significantly stimulate ROS production in many types of cells $(16,29,45,46)$, and the present authors have previously demonstrated this $(43,44)$. In the present study, the experiments using ROS inhibitors confirmed that ROS is essential for the induction of IL-6 secretion by either AGE or LPS in J774 macrophages. In human THP-1 macrophages and umbilical vein endothelial cells, AGE induces ROS generation via the RAGE/NF- $\mathrm{B}$ pathway $(45,46)$ and LPS induces a TLR4-dependent upregulation in ROS production (47). These 
previous results and the results of the present study indicate that ROS may be harmful mediators of inflammation.

Resveratrol has attracted wide attention due to its anti-inflammatory, anti-aging and antioxidant effects in animal models $(22,24)$. It was previously reported that resveratrol inhibits LPS-induced NF- $\mathrm{NB}$ translocation and inflammatory cytokine secretion in the murine Raw264.7 macrophage cell line (48). In the present study, resveratrol was demonstrated to significantly inhibit LPS- and AGE-induced IL-6 secretion in J774 macrophages. Furthermore, resveratrol significantly suppressed intracellular IL- 6 production and IL-6 mRNA expression, indicating that the beneficial role of resveratrol in inflammatory responses is achieved via inhibitory control at transcriptional levels, resulting in an attenuation of pro-inflammatory cytokine production.

Resveratrol is known to stimulate SIRT1 and AMPK, which have been shown to serve many similar functions as energy sensors and in regulating the nutrient status and stress response $(22,25)$. SIRT1 activation by resveratrol improves mitochondrial function and mitochondrial biogenesis, and increases ATP production (25). Furthermore, in a study using SIRT1 knockout mice and SIRT1 transgenic mice, Price et al (25) demonstrated that SIRT1 is essential for AMPK activation and resveratrol function. In the present study, treatment with Ex527 (a SIRT1 inhibitor) canceled the anti-inflammatory effect of resveratrol in J774 macrophages. A previous study found that downregulation of SIRT1 expression resulted in the anti-inflammatory role of resveratrol being eliminated in human amnion cells (49), and furthermore, a reduction in SIRT1 activity has been demonstrated to induce hyperacetylation of $\mathrm{NF}-\kappa \mathrm{B}(50)$. These data suggest that resveratrol-induced SIRT1 has a pivotal role in regulating $\mathrm{NF}-\kappa \mathrm{B}$ dependent pro-inflammatory mediator production.

AMPK is a metabolic regulator that promotes insulin sensitivity and fatty acid oxidation (22), and resveratrol activates AMPK in cell culture and in vivo (25). Using AMPK knockout mice, Yi et al (48) reported that AMPK is required for many of the effects of resveratrol on metabolic function. The present study demonstrated the importance of AMPK activation via the inhibitory effect of treatment with AICAR (AMPK activator) on IL-6 secretion in J774 macrophages. Yi et al (48) reported that AICAR suppresses LPS-induced TNF- $\alpha$ secretion in the Raw264.7 macrophage cell line, and that treatment with an AMPK inhibitor (compound C) also decreases TNF- $\alpha$ secretion in LPS-treated Raw264.7 macrophages. Similarly, a previous study demonstrated that compound C decreases IL-6, IL-1 $\beta$, and TNF- $\alpha$ secretion in microglia (51). Therefore, Yi et al (48) speculated the importance of the dual roles of AMPK in macrophage-derived inflammation. Further studies are required for a detailed clarification of the functions of AMPK in macrophages.

A limitation of the present study is that it was not possible to examine whether AGE and LPS induce excessive inflammatory responses resulting in pregnancy complications in vivo, and whether resveratrol improves these pregnancy complications. With respect to this, Furuya et al (52) reported that resveratrol treatment suppresses inflammatory cytokine production induced by LPS in mice, resulting in protection against preterm birth. Also, resveratrol significantly reduces accumulation and inflammation of macrophages induced by LPS, resulting in the improvement of kidney function in vivo (53). Therefore, in future studies, the role of AGE, LPS, and resveratrol in inflammatory responses associated with pathophysiology of pregnancy should be examined in vivo. Another limitation is that the effects of AGE and LPS on cells associated with reproduction, such as trophoblast/placental cells or uterus cells, were not studied, nor were the detailed interaction of these cells with macrophages. Further investigations are required to clarify these mechanisms.

In conclusion, the results of the present study demonstrated that exposure to AGE and LPS results in IL-6 production, which is dependent on NF- $\kappa \mathrm{B}$ activation and ROS production through RAGE and/or TLR4, in a murine J774 macrophage cell line. Additionally, resveratrol is effective in regulating inflammatory responses associated with SIRT1 and AMPK activation in macrophages.

\section{Acknowledgements}

The present study was supported by the Japan Society for the Promotion of Science through Scientific Research (grant no. 15K07783) and the Strategic Research Project from Tokyo University of Agriculture. The present authors would like to thank Enago (Crimson Interactive K.K., Tokyo, Japan) for the English language review.

\section{References}

1. Laresgoiti-Servitje E: A leading role for the immune system in the pathophysiology of preeclampsia. J Leukoc Biol 94: 247-257, 2013.

2. Faas MM, Spaans F and De Vos P: Monocytes and macrophages in pregnancy and pre-eclampsia. Front Immunol 5: 298, 2014.

3. Care AS, Diener KR, Jasper MJ, Brown HM, Ingman WV and Robertson SA: Macrophages regulate corpus luteum development during embryo implantation in mice. J Clin Invest 123: 3472-3487, 2013.

4. Sacks GP, Studena K, Sargent K and Redman CW: Normal pregnancy and preeclampsia both produce inflammatory changes in peripheral blood leukocytes akin to those of sepsis. Am J Obstet Gynecol 179: 80-86, 1998.

5. Melgert BN, Spaans F, Borghuis T, Klok PA, Groen B, Bolt A, de Vos P, van Pampus MG, Wong TY, van Goor H, et al: Pregnancy and preeclampsia affect monocyte subsets in humans and rats. PLoS One 7: e45229, 2012.

6. Lau SY, Guild SJ, Barrett CJ, Chen Q, McCowan L, Jordan V and Chamley LW: Tumor necrosis factor-alpha, interleukin-6, and interleukin-10 levels are altered in preeclampsia: A systematic review and meta-analysis. Am J Reprod Immunol 70: 412-427, 2013.

7. Robertson SA, Skinner RJ and Care AS: Essential role for IL-10 in resistance to lipopolysaccharide-induced preterm labor in mice. J Immunol 177: 4888-4896, 2006.

8. Romero R, Sirtori M, Oyarzun E, Avila C, Mazor M, Callahan R, Sabo V, Athanassiadis AP and Hobbins JC: Infection and labor. V. Prevalence, microbiology, and clinical significance of intraamniotic infection in women with preterm labor and intact membranes. Am J Obstet Gynecol 161: 817-824, 1989.

9. Meis PJ, Goldenberg RL, Mercer B, Moawad A, Das A, McNellis D, Johnson F, Iams JD, Thom E and Andrews WW: The preterm prediction study: Significance of vaginal infections. National Institute of Child Health and Human Development Maternal-Fetal Medicine Units Network. Am J Obstet Gynecol 173: 1231-1235, 1995.

10. Bo QL, Chen YH, Yu Z, Fu L, Zhou Y, Zhang GB, Wang H, Zhang $\mathrm{ZH}$ and Xu DX: Rosiglitazone pretreatment protects against lipopolysaccharide-induced fetal demise through inhibiting placental inflammation. Mol Cell Endocrinol 423: 51-59, 2016.

11. John WG and Lamb EJ: The Maillard or browning reaction in diabetes. Eye (Lond) 7: 230-237, 1993.

12. Lotze MT and Tracey KJ: High-mobility group box 1 protein (HMGB1): Nuclear weapon in the immune arsenal. Nat Rev Immunol 5: 331-342, 2005. 
13. ChekirC,Nakatsuka M,Noguchi S, Konishi H,Kamada Y, Sasaki A Hao L and Hiramatsu Y: Accumulation of advanced glycation end products in women with preeclampsia: Possible involvement of placental oxidative and nitrative stress. Placenta 27: 225-233, 2006.

14. Naruse K, Sado T, Noguchi T, Tsunemi T, Yoshida S, Akasaka J, Koike N, Oi H and Kobayashi H: Peripheral RAGE (receptor for advanced glycation endproducts)-ligands in normal pregnancy and preeclampsia: Novel markers of inflammatory response. J Reprod Immunol 93: 69-74, 2012.

15. Hao L, Noguchi S, Kamada Y, Sasaki A, Matsuda M, Shimizu K, Hiramatsu Y and Nakatsuka M: Adverse effects of advanced glycation end products on embryonal development. Acta Med Okayama 62: 93-99, 2008.

16. Huang QT, Zhang M, Zhong M, Yu YH, Liang WZ, Hang LL, Gao YF, Huang LP and Wang ZJ: Advanced glycation end products as an upstream molecule triggers ROS-induced sFlt-1 production in extravillous trophoblasts: A novel bridge between oxidative stress and preeclampsia. Placenta 34: 1177-1182, 2013.

17. Akira S, Uematsu $S$ and Takeuchi O: Pathogen recognition and innate immunity. Cell 124: 783-801, 2006.

18. Ibrahim ZA, Armour CL, Phipps S and Sukkar MB: RAGE and TLRs: Relatives, friends or neighbours? Mol Immunol 56 739-744, 2013.

19. Szmitko PE and Verma S: Cardiology patient pages. Red wine and your heart. Circulation 111: e10-e11, 2005.

20. Ponzo V, Soldati L and Bo S: Resveratrol: A supplementation for men or for mice? J Transl Med 12: 158, 2014

21. Jang M, Cai L, Udeani GO, Slowing KV, Thomas CF, Beecher CW, Fong HH, Farnsworth NR, Kinghorn AD, Mehta RG, et al: Cancer chemopreventive activity of resveratrol, a natural product derived from grapes. Science 275: 218-220, 1997.

22. Baur JA, Pearson KJ, Price NL, Jamieson HA, Lerin C, Kalra A Prabhu VV, Allard JS, Lopez-Lluch G, Lewis K, et al: Resveratro improves health and survival of mice on a high-calorie diet. Nature 444: 337-342, 2006

23. Wang F, Tian X, Zhang L, He C, Ji P, Li Y, Tan D and Liu G: Beneficial effect of resveratrol on bovine oocyte maturation and subsequent embryonic development after in vitro fertilization. Fertil Steril 101: 577-586, 2014.

24. Valenzano DR, Terzibasi E, Genade T, Cattaneo A, Domenici L and Cellerino A: Resveratrol prolongs lifespan and retards the onset of age-related markers in a short-lived vertebrate. Curr Biol 16: 296-300, 2006.

25. Price NL, Gomes AP, Ling AJ, Duarte FV, Martin-Montalvo A North BJ, Agarwal B, Ye L, Ramadori G, Teodoro JS, et al: SIRT1 is required for AMPK activation and the beneficial effects of resveratrol on mitochondrial function. Cell Metab 15: 675-690, 2012

26. Kawasaki Y, Aoki Y, Magata F, Miyamoto A, Kawashima C, Hojo T, Okuda K, Shirasuna K and Shimizu T: The effect of single nucleotide polymorphisms in the tumor necrosis factor- $\alpha$ gene on reproductive performance and immune function in dairy cattle. J Reprod Dev 60: 173-178, 2014.

27. Livak KJ and Schmittgen TD: Analysis of relative gene expression data using real-time quantitative PCR and the 2(-Delta Delta C(T)) Method. Methods 25: 402-408, 2001

28. Brasier AR: The nuclear factor-kappaB-interleukin-6 signalling pathway mediating vascular inflammation. Cardiovasc Res 86 211-218, 2010

29. Yin QQ, Dong CF, Dong SQ, Dong XL, Hong Y, Hou XY, Luo DZ, Pei JJ and Liu XP: AGEs induce cell death via oxidative and endoplasmic reticulum stresses in both human SH-SY5Y neuroblastoma cells and rat cortical neurons. Cell Mol Neurobiol 32: 1299-1309, 2012.

30. Lin JK and Tsai SH: Chemoprevention of cancer and cardiovascular disease by resveratrol. Proc Natl Sci Counc Repub China B 23: 99-106, 1999.

31. Berbaum K, Shanmugam K, Stuchbury G, Wiede F, Körner H and Munch G: Induction of novel cytokines and chemokines by advanced glycation endproducts determined with a cytometric bead array. Cytokine 41: 198-203, 2008.

32. Lappas M, Permezel M and Rice GE: Advanced glycation endproducts mediate pro-inflammatory actions in human gestational tissues via nuclear factor-kappaB and extracellular signal-regulated kinase 1/2. J Endocrinol 193: 269-277, 2007.

33. Liu J, Zhao S, Tang J, Li Z, Zhong T, Liu Y, Chen D, Zhao M, Li Y, Gong X, et al: Advanced glycation end products and lipopolysaccharide synergistically stimulate proinflammatory cytokine/chemokine production in endothelial cells via activation of both mitogen-activated protein kinases and nuclear factor-kappaB. FEBS J 276: 4598-4606, 2009.
34. Chen YJ, Sheu ML, Tsai KS, Yang RS and Liu SH: Advanced glycation end products induce peroxisome proliferator-activated receptor $\gamma$ down-regulation-related inflammatory signals in human chondrocytes via Toll-like receptor-4 and receptor for advanced glycation end products. PLoS One 8: e66611, 2013.

35. Shim E and Babu JP: Glycated albumin produced in diabetic hyperglycemia promotes monocyte secretion of inflammatory cytokines and bacterial adherence to epithelial cells. J Periodontal Res 50: 197-204, 2015.

36. Dragone T, Cianciulli A, Calvello R, Porro C, Trotta T and Panaro MA: Resveratrol counteracts lipopolysaccharide-mediated microglial inflammation by modulating a SOCS-1 dependent signaling pathway. Toxicol In Vitro 28: 1126-1135, 2014

37. Jin X, Yao T, Zhou Z, Zhu J, Zhang S, Hu W and Shen C: Advanced Glycation End Products Enhance Macrophages Polarization into M1 Phenotype through Activating RAGE/NF-кB Pathway. Biomed Res Int 2015: 732450, 2015

38. Schroder K, Zhou R and Tschopp J: The NLRP3 inflammasome: A sensor for metabolic danger? Science 327: 296-300, 2010.

39. Takahashi M: Role of the inflammasome in myocardial infarction. Trends Cardiovasc Med 21: 37-41, 2011

40. Ott C, Jacobs K, Haucke E, Navarrete Santos A, Grune T and Simm A: Role of advanced glycation end products in cellular signaling. Redox Biol 2: 411-429, 2014.

41. Vénéreau $E$, Ceriotti $C$ and Bianchi ME: DAMPs from cell death to new life. Front Immunol 6: 422, 2015.

42. Cheng A, Dong Y, Zhu F, Liu Y, Hou FF and Nie J: AGE-LDL activates Toll like receptor 4 pathway and promotes inflammatory cytokines production in renal tubular epithelial cells. Int J Biol Sci 9: 94-107e, 2013.

43. Shirasuna K, Seno K, Ohtsu A, Shiratsuki S, Ohkuchi A, Suzuki H, Matsubara S, Nagayama S, Iwata $\mathrm{H}$ and Kuwayama T: AGEs and HMGB1 increase inflammatory cytokine production from human placental cells, resulting in an enhancement of monocyte migration. Am J Reprod Immunol 75: 557-568, 2016.

44. Shirasuna K, Takano H, Seno K, Ohtsu A, Karasawa T, Takahashi M, Ohkuchi A, Suzuki H, Matsubara S, Iwata H and Kuwayama T: Palmitic acid induces interleukin-1 $\beta$ secretion via NLRP3 inflammasomes and inflammatory responses through ROS production in human placental cells. J Reprod Immunol 116: 104-112, 2016

45. Ishibashi Y, Matsui T, Takeuchi M and Yamagishi S: Rosuvastatin blocks advanced glycation end products-elicited reduction of macrophage cholesterol efflux by suppressing NADPH oxidase activity via inhibition of geranylgeranylation of Rac-1. Horm Metab Res 43: 619-624, 2011.

46. Feng L, Zhu MM, Zhang MH, Wang RS, Tan XB, Song J, Ding SM, Jia XB and Hu SY: Protection of glycyrrhizic acid against AGEs-induced endothelial dysfunction through inhibiting RAGE/NF- $\kappa$ B pathway activation in human umbilical vein endothelial cells. J Ethnopharmacol 148: 27-36, 2013.

47. Lorne E, Dupont H and Abraham E: Toll-like receptors 2 and 4: Initiators of non-septic inflammation in critical care medicine? Intensive Care Med 36: 1826-1835, 2010.

48. Yi CO, Jeon BT, Shin HJ, Jeong EA, Chang KC, Lee JE, Lee DH, Kim HJ, Kang SS, Cho GJ, et al: Resveratrol activates AMPK and suppresses LPS-induced NF- $\mathrm{BB}$-dependent COX-2 activation in RAW 264.7 macrophage cells. Anat Cell Biol 44: 194-203, 2011

49. Lappas M, Mitton A, Lim R, Barker G, Riley C and Permezel M: SIRT1 is a novel regulator of key pathways of human labor. Biol Reprod 84: 167-178, 2011.

50. Nakamaru Y, Vuppusetty C, Wada H, Milne JC, Ito M, Rossios C, Elliot M, Hogg J, Kharitonov S, Goto H, et al: A protein deacetylase SIRT1 is a negative regulator of metalloproteinase-9. FASEB J 23: 2810-2819, 2009

51. Labuzek K, Liber S, Gabryel B, Bułdak L and Okopień B: Ambivalent effects of compound $\mathrm{C}$ (dorsomorphin) on inflammatory response in LPS-stimulated rat primary microglial cultures. Naunyn Schmiedebergs Arch Pharmacol 381: 41-57, 2010.

52. Furuya H, Taguchi A, Kawana K, Yamashita A, Inoue E, Yoshida M, Nakamura H, Fujimoto A, Inoue T, Sato M, et al: Resveratrol protects against pathological preterm birth by suppression of macrophage-mediated inflammation. Reprod Sci 22: 1561-1568, 2015.

53. Chen L, Yang S, Zumbrun EE, Guan H, Nagarkatti PS and Nagarkatti M: Resveratrol attenuates lipopolysaccharide-induced acute kidney injury by suppressing inflammation driven by macrophages. Mol Nutr Food Res 59: 853-864, 2015. 